\title{
Patient Centered Radiology - An Introduction in Form of a Narrative Review
}

\section{Patientenzentrierte Radiologie - Eine Hinführung durch ein narratives Review}

Authors

Andreas G. Schreyer ${ }^{1}$, Katharina Schneider ${ }^{1}$, Lena Marie Dendl', Philipp Jaehn², Isabel Molwitz ${ }^{3}$, Kerstin Westphalen ${ }^{4}$, Christine Holmberg ${ }^{2}$

Affiliations

1 Institute for Diagnostic and Interventional Radiology, Brandenburg Medical School Theodor Fontane, Brandenburg a. d. Havel, Germany

2 Institute of Social Medicine and Epidemiology, Brandenburg Medical School Theodor Fontane, Brandenburg a. d. Havel, Germany

3 Department of Diagnostic and Interventional Radiology and Nuclear Medicine, University Medical Center Hamburg-Eppendorf, Hamburg, Germany

4 Department of Diagnostic and Interventional Radiology, DRK Kliniken Berlin Köpenick, Berlin, Germany

Key words

health policy and practice, socioeconomic issues, narrative review, patient centered radiology

received 27.09.2021

accepted 03.01.2022

published online 23.02.2022

Bibliography

Fortschr Röntgenstr 2022; 194: 873-881

DOI 10.1055/a-1735-3552

ISSN 1438-9029

(C) 2022. Thieme. All rights reserved.

Georg Thieme Verlag KG, Rüdigerstraße 14,

70469 Stuttgart, Germany

Correspondence

Herr Prof. Andreas G. Schreyer

Institute for Diagnostic and Interventional Radiology,

Brandenburg Medical School Theodor Fontane,

Hochstrasse 29, 14770 Brandenburg a. d. Havel, Germany

Tel.: $+49 / 3381 / 412600$

Fax: $+49 / 3381 / 412609$

andreas.schreyer@mac.com

\section{ABSTRACT}

Background Patient centered radiology represents a crucial aspect for modern sustainable radiology. The definition of patient-centered consists of a focus on patients' individual values and wishes with a respectful integration in medical decisions. In this narrative review we try to give a practical introduction into this complex topic with the extension to a person-centered radiology, which additionally encompasses values and wishes of radiological and other medical colleagues.

Methods Medline search between 2010 and 2021 using "patient-centered radiology" with additional subjective selection of articles for this narrative review.

Results Regarding patients' experiences the main literature focus were patients' fears of examinations (movement restrictions, uncertainty). Most patients would prefer a direct communication with the radiologist after the examination. Regarding interdisciplinary communication the radiological expertise and quality is highly appreciated; however, there was a general wish for more structured- or itemized reporting. Concerning working conditions radiologists were satisfied despite high psychosocial working pressure.

Conclusion Most of the literature on this topic consists of surveys evaluating the current state. Studies on interventions such as improved information before examinations or patientreadable reports are still scarce. There is a dilemma between an increasing radiological workload and the simultaneous wish for more patient-centered approaches such as direct radiologist-patient communications in the daily routine. Still on our way to a more value-based radiology we have to focus on patient communications and a patient-centered medicine.

\section{Key Points:}

- Patient centered radiology has a focus on the integration of patients' individual values and wishes in their decisions.

- Radiologists are clinicians, who an additional diagnostic and therapeutic surplus for patients and referring physicians.

- The recent literature on this topic consists basically on the evaluation of the current status.

- Most patients prefer a direct communication with the radiologist.

- To gain a "value based" radiology we to focus on an optimized communication with patients and referring physicians. 


\section{Citation Format}

- Schreyer AG, Schneider K, Dendl LM et al. Patient Centered Radiology - An Introduction in Form of a Narrative Review. Fortschr Röntgenstr 2022; 194: 873-881

\section{ZUSAMMENFASSUNG}

Hintergrund Patientenzentrierte Radiologie stellt einen entscheidenden Aspekt einer modernen nachhaltigen Radiologie dar. Patientenzentriertheit ist dabei definiert als eine Fokussierung auf persönliche Werte und Wünsche der Patienten mit respektvoller Integration in medizinische Entscheidungen. In diesem narrativen Review wollen wir eine praktische Hinführung auf dieses umfassende Thema mit der inhaltlichen Erweiterung auf eine personenzentrierte Radiologie, die auch die Werte und Wünsche von Mitarbeitern und zuweisenden Kollegen berücksichtigt, versuchen.

Methode Medline-Suche zwischen 2010 bis 2021 unter dem Begriff „patient-centered radiology“ mit subjektiver Auswahl und Ergänzung im Sinne eines narrativen Reviews.

Ergebnisse Beim Erleben des Untersuchungsablaufes stand die Angst der Patienten vor Untersuchungen (Bewegungseinschränkung, Ungewissheit) im Fokus der Literatur. Nach Abschluss der Untersuchung wünscht sich ein Großteil der Pa- tienten ein Gespräch mit dem Radiologen. In der Kommunikation mit zuweisenden Fächern wird die radiologische Expertise und Qualität insgesamt positiv wahrgenommen, wobei hier der Wunsch nach mehr strukturierter Befundung bzw. „itemized reporting " deutlich wird. Hinsichtlich der Arbeitssituation in der Radiologie zeigt sich eine hohe Zufriedenheit und Identifikation mit dem Fach trotz hoher psychosozialer Arbeitsbelastung.

Schlussfolgerung Der Großteil der Publikationen zum Thema besteht aus Befragungen zur Erhebung des Ist-Zustandes. Wissenschaftliche Evaluationen mit Interventionen wie etwa der verbesserten Information vor Untersuchungen oder der Einführung von verständlichen patientenlesbaren Befunden existieren gegenwärtig nur vereinzelt. Das Dilemma der wachsenden Arbeitsbelastung durch weiter zunehmende Bildgebung in der Radiologie bei gleichzeitigem Wunsch nach mehr Patientenzentriertheit u. a. durch Arzt-PatientenGespräche ist im Arbeitsalltag gegenwärtig nur schwer zu lösen. Doch ist auf dem Weg zu einer wertebasierten Radiologie die Rückbesinnung auf ärztliche Tätigkeiten u. a. mit dem Fokus auf Kommunikation und Menschlichkeit durch Patientenzentrierung essenziell.
For better readability, the manuscript refrains from using feminine and masculine forms of language simultaneously and uses the generic masculine where appropriate. All personal designations apply equally to all genders.

\section{Introduction}

The phrase "patient-centered radiology" may initially seem like an empty platitude to many radiologists. Mentioning this topic in professional circles sometimes leads to the reflexive response that for us as radiologists and physicians, the patient is always the focus. At first glance, this may seem to be true in terms of our feelings and understanding of ourselves as physicians, but a closer look reveals that reality is often different. In the context of the constraints of medical-economic conditions and the simultaneous pressure of coping with an increasing number of radiological examinations, in daily practice and reality a contradiction often arises to the sought-after ideal image.

Patient-centered medicine means placing the individual values and wishes of patients at the center of medical practice [1]. The Institute of Medicine (USA) succinctly defines patient-centered medicine as “... respectful of, and responsive to, individual patient preferences, needs and values, and ensuring that patient values guide all clinical decisions ..." [2]. In this case, the autonomy of the patient plays a central role: the physician is no longer the sole decider regarding treatment, further examinations and treatment, but also the patient participates in the context of his or her individual health history.
Patient-centered radiology, however, should not be reduced to the doctor-patient conversation. The perception and "experience" of radiology rely on a complex process chain, some of which is intrinsic to the subject, starting with examination registration (electronic forms in the hospital information system or online patient portals or telephone appointment) through the medical consultation, performance of the examination and subsequent discussion of findings.

Patient interviews have shown that satisfaction and trust during contact are primarily based on the perception of medical expertise and humaneness [3]. Regarding the "humaneness" in the interaction, the spatial environment and contact time, but also mutual respect as well as understanding for the individual situation are specifically emphasized. This leads to increased well-being of the patients and the psychological and social aspects of the disease and the recovery process find a suitable place in the treatment $[4,5]$.

In 2006 the Radiological Society of North America (RSNA) established the first steering committee and scientific meetings on the subject of patient-centered radiology at its annual congress under the slogan "use it or lose it". The first organized workshops in 2009 were primarily focused on offering systematic training in communication with patients and providing scientific support. In 2012, the RSNA put the website www.radiologycares. org online, which offered collected literature and advanced training courses on the subject. In the RSNA's last in-person event of 2019, the topic was identified as one of the major themes spanning the event in congress President Valerie P. Jackson's opening remarks, titled "A Matter of Perspective: Putting a New Lens on 
Our Patient Interactions". Likewise, in the German-speaking radiological community, the topic of patient-centeredness has gained in importance in recent years in terms of perception and, in part, also research.

The European Society of Radiology (ESR) in a recent position paper describes its approach to "value-based" radiology [6]. The topic is also active in the German Radiological Society (DRG) through a focus on content at the 103 rd German Congress of Radiology in 2022 under the motto "Living Diversity - Shaping the Future". In the context of the topic sustainability, the social aspects of radiology in the interaction with patients should be emphasized. For this reason, a new working group on sustainability was established in the German Radiological Society (DRG) in November 2020, which will work on this topic systematically, scientifically and practically. Broken down to its basic principle, sustainability is to be understood that no more may be consumed than grows back or regenerates. In this context, the term "sustainability" should not only be used one-dimensionally based on the principle of resource utilization with preserved regenerative capacity, as originally known from forestry [7]; instead, we favor the more complex "three-pillar model" for our medical specialty, which in principle consists of three partly overlapping concepts of ecology, economy and social aspects ( $\triangleright$ Fig. 1) [8]. The ecological and economic aspects of sustainability can be considered selfexplanatory to a large extent. In the context of the three-pillar model, sustainability also means not only limiting radiology to economics and ecology and benchmarking it externally, but also taking into account the social aspects of our discipline [9]. A crucial core of this will be the radiologist's interaction with the patient. However, the concept should be understood not only as "patient-centered radiology" but expanded to "people-centered radiology". Adequate and appreciative interaction should not only characterize radiologists' communication with patients, but by extension should also encompass radiologists' or medical-technical assistants' working methods and training, as well as radiologists' interaction with their medical partners from all disciplines.

In order to provide the radiological community in Germany the opportunity not to dismiss the term patient-centeredness or person-centeredness as an empty phrase, but to work together to implement it and incorporate it into their daily work and practice, as a newly-founded working group in the German Radiological Society (www.nachhaltigkeit.drg.de), we have striven to first create the current situation in a literature review from 2010-08/2021 in the sense of a narrative review. We have primarily identified articles which were indexed under the term "patient-centered radiology" in Pubmed. A scientific and practical introduction to the topic has been provided based on the literature compilation ( Table 1).

\section{Radiology as a Clinical Discipline}

Regarding the simple statement that radiology is an independent clinical discipline, a simple Google search with automatic completion of the search query can be disturbing at first. An input in the search engine "Radiologist are ..." is currently completed by the

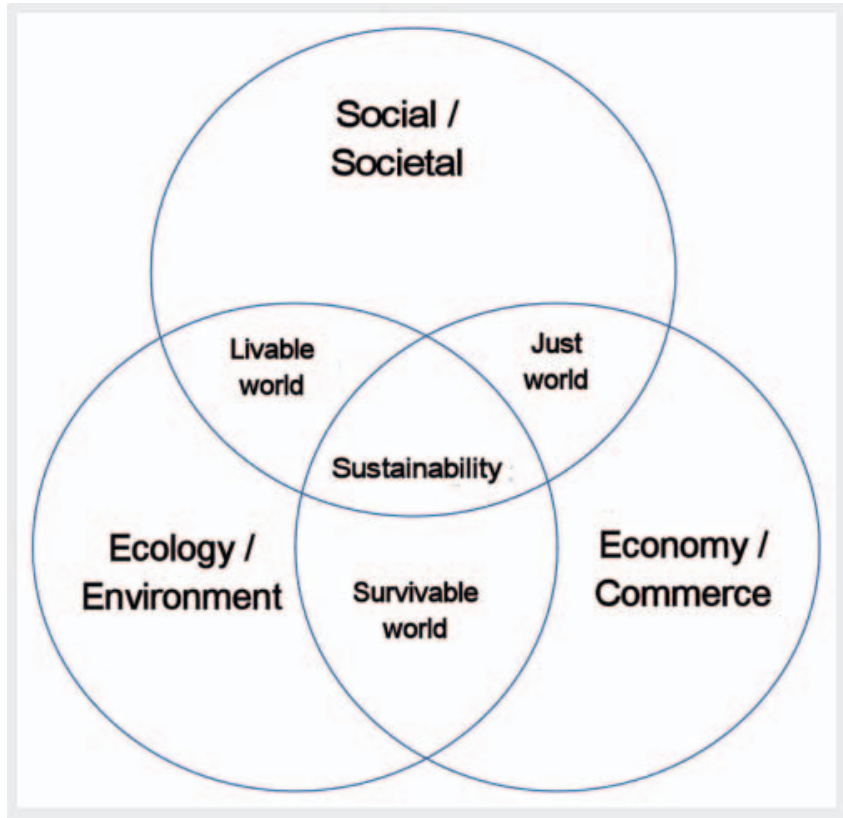

- Fig. 1 Modification of the so called "3-column-model" of sustainability with overlapping subgroups regarding social aspects, ecology and economy [8].

- Table 1 Summary of important topics in patient- or person-centered radiology with reference to important literature on the subtopics.

(Patient) Experience of radiological examinations

Fear of the examination [17]

Limited freedom of movement when positioned in large equipment [18]

Anxiety due to uncertainty until disclosure of findings $[18,19,21]$

(Patient) Communication of radiological findings after the examination

Personal discussion of findings [20, 24, 30-32]

Comprehension of medical terminology and examination result [36, 37]

(Referring physician) Communication with radiology department

Appreciation of radiological findings and work [12]

Quality of intercollegial communication [12, 39]

Professional motivation and satisfaction in radiology

Professional stress level [45]

Professional appreciation and recognition $[12,45]$

most frequent search queries by users such that it can be seen that many Internet queries want to clarify whether radiologists are physicians at all. Likewise, medical literature often distinguishes between "clinicians" and "radiologists". This linguistic distinction alone shows that for many patients and physicians in the medical establishment, the radiologist is not considered a clinically involved physician [10]. In the international English-language literature, these divisions between radiologists and clinicians find 
expression in headings such as "The Relationship Between Radiologists and Clinicians" [11]. It seems even more disturbing that even in radiology journals and lectures, the distinction between clinicians and radiologists is consistently perpetuated [12]. And in everyday clinical practice, we as radiologists reinforce this completely false and misleading dichotomy by talking about "clinicians" who want something from us. However, this way of speaking almost automatically makes us the opposite pole, "nonclinicians".

Strictly speaking, a distinction is made in modern medicine between clinicians, i. e. physicians who care for patients, and physicians whose focus is on education, research or administrative activities. Radiologists probably rarely occur in patients' perception of physicians, which may be due, among other things, to the fact that patients rarely visit a radiology department directly, but are usually referred, and during examinations frequently do not meet the radiologist in person. There are different degrees of direct patient contact depending on the subspecialty - radiologists, however, are clearly clinicians, who, whether in procedures, mammography, ultrasound or conventional X-ray or CT and MRI diagnostics, have an immediate and direct clinical responsibility for each individual patient. As radiologists, we have a self-image that we are not theorists who just look at images, but clinical physicians who add value to patients and referring physicians based on the patients' history and complex clinical context.

As radiologists we should consider eliminating this partly self-selected false distinction between clinicians and radiologists linguistically, in order not to become victims of a self-fulfilling prophecy. Terminology such as "referring physician" or naming the medical discipline or department could be helpful here.

There are no systematic studies of the extent to which radiologists are perceived as physicians. However, as radiologists, we also have a personal responsibility in communicating with patients, colleagues, and referring physicians to accept and demand the role in direct care.

\section{Patients' Experience of Radiological Examinations}

Patient-centered radiology means much more than just talking to the patient during the course of the examination, rather, patientcentered radiology aims to prepare patients for the examination in advance, for example, through patient education and information in social media or online presence $[13,14]$. This perception ranges from the scheduling and registration process through the experience and knowledge gained during imaging or intervention to the creation of reports, reporting of findings, transparent invoicing and the further communication process in the scheduling of follow-up examinations. Patient-centered radiology does not only mean communicating the results of the examination in person, but must also be seen as an optimization of the overall experience in the radiology department.

To our knowledge, there have been no systematic studies of the pre-examination experience, such as the registration process or information perception prior to radiological examinations. Po- tenzially, multimedia information prior to the examination, such as videos on websites or in the waiting area or virtual walkthroughs of the examination rooms, would be one way to reduce uncertainty and anxiety regarding radiological examinations. However, sufficient studies are currently not available on this topic. However, as part of the radiology examination preparation, one of the areas evaluated was the understanding of risk during CT examinations [15]. For example, a study of the CT informed consent process found that patients benefited primarily from an individualized educational discussion, with a significant relationship existing between educational status and risk comprehension [15]. A study of the subjective perception of the waiting time in the radiology department at a university clinic through regular or optimized care came to the result that more intensive care (more information and personal care, beverages, etc.) while waiting subjectively estimated the waiting time to be shorter. As a quality criterion for good radiological care, however, waiting time was rated as important by only $24 \%$ of respondents - more relevant for over $40 \%$ of participants was a detailed discussion with the radiologist before the examination [16].

The perception of a radiological examination by patients has already been examined in many ways in the literature. For example, Munn et al. in a 2011 systematic review, showed that $71.6 \%$ found anxiety or panic to be the most common problem during an MRI scan [17]. This applies not only to the actual performance of the examination, but also to the time required to report the findings [18]. On the whole, emotions such as fear and uncertainty seem to play a major role in the subjective experience of a radiological examination.

For example, during examinations with large equipment (CT, MRI), patients find the limited mobility intimidating [17]. The combination of the spatial conditions and loud noises, such as those that occur during an MRI, can trigger a sense of threat and cause anxiety and stress [19]. In addition, the patients must lie as still as possible for good quality images; not being able to move creates additional discomfort [19]. For some patients, an accompanying feeling of loss of control can be reduced by providing detailed information beforehand. The emergency button, with which the examination can be aborted, as well as occasional acoustic contact with the examiner, is felt to be helpful and reassuring [10].

The time after the examination until the discussion of the findings is also emotionally charged for radiological patients. The wait for a possible diagnosis made by imaging is an immense stressor for those involved. A subsequent announcement of a potentially serious diagnosis is associated with a strong emotional reaction that can be experienced as traumatic [18].

Thus, $75 \%$ of patients would like to be notified of the findings within 30 minutes [20]. The waiting time as such, both before and after the examination, has a great influence on the satisfaction regarding a visit to the radiology department [11]. Follow-up examinations, for example for oncological patients, are perceived as less emotionally stressful - in a way, a routine is created: patients know their diagnosis and the course of the examination [18]. In addition, the patient's level of education affects how they handle a radiological examination. Knowledge about the exami- 
nation, possible diagnoses and therapies reduces the anxiety level [18].

However, patients' own research can lead to problems. Patients may be misinformed about examinations as a result of anecdotes from their friends and relatives or, for example, Internet research they have conducted themselves [17]. Misconceptions thus formed can result in an attitude that is difficult to fully eliminate even through extensive counseling. An example of this is that the anxiety level in patients is higher before an MRI than before a CT scan [18], which objectively seen is paradoxical, since an MRI produces no radiation and involves less risk. The reason for this could be that CT as a form of radiological diagnostics is more common in everyday life and therefore better known than MRI. Theoretically, however, the longer examination time and the confinement of the gantry in the MRI could also be partly responsible. In general the informed consent process seems to be a multilayered element of individual perception. Thus, comprehensive background information is fundamental for a positive feeling with which the patient then faces the examination [17, 21]. In the future, this could be improved by multimedia provision of informational and educational videos as well as written material [22, 23]. Despite written information, patients may have gaps in their knowledge if they misread or did not understand sections of the material [19]. In addition, patients prefer to be informed about the procedure, risks, contrast media, etc. in personal contact, as queries are possible, and concerns and uncertainties can be addressed [17, 19, 21]. Even after comprehensive written and oral information, all patients still report a certain basic level of nervousness and tension before a radiological examination [19].

\section{Communication with Patients after the Examination}

Interaction between radiologists and patients is considered a core element of patient-centered radiology [24].

Early publications from 2007 and 2009 by L. Berlin offer an interesting image of relevant attitudes $[25,26]$. Cited is a 1966 letter to the editor in Radiology in which a North Carolina radiologist writes, (loosely translated), “... we as radiologists do not have to listen to long and vague descriptions of patients' symptoms or even perform complete physical examinations. Anyone wanting to do that should become anything but a radiologist ..." [27]. This quote illustrates the historical attitude of some radiologists in the early $1970 \mathrm{~s}$. Based on the requirements of mammography screening in the USA to personally inform patients of the findings within a defined period of time, Berlin sees a general obligation to provide personal notification of findings in direct patient contact. He emotionally appeals to radiologists to primarily serve the patient and have an ethical responsibility.

The extent to which personal contact with the radiologist is relevant for the patient and how this should ideally be structured has also been investigated. In one study, for example, $84 \%$ of outpatient ultrasound patients would like to have a discussion of findings directly with the radiologist [28]. A study by Schreiber et al. showed that the majority of patients would like to receive the in- formation directly from the radiologist after the examination. In this regard, $92 \%$ of those questioned stated that they would like to receive normal findings directly from the radiologist and $87 \%$ would like to have a discussion with respect to pathological findings [29]. A German written survey demonstrated that $48 \%$ of patients and $59 \%$ of referring physicians wanted a doctor-patient discussion with the radiologist to take place after the examination [30]. At the same time, patients in that study wanted to receive the results of the examination within 30 minutes.

A consideration of all published articles regarding the desire for a personal conversation with the radiologist in the case of unremarkable findings, the large spread between 12\% [31] and $94 \%$ [28] is striking. This suggests an influence by the choice of study design. In an anonymized theoretical survey after CT and MRI examinations, $34 \%$ of patients wanted to be called by the referring physician and $12 \%$ by the radiologist if the findings were hypothetically normal [31]. Only $2.6 \%$ of the study participants wanted a personal discussion in the case of normal findings. In the event of pathological findings, however, the request for telephone reporting of findings was higher, at $49.8 \%$ by the referring physician and $14.4 \%$ by the radiologist. These results from an online survey of patients with hypothetical questions are then contrasted with the results published in 2019 by Gutzeit et al. based on actual situations [32], in which 2 groups of 101 patients each were compared, with only one group having a personal assessment conversation following their MRI examination. Across both groups, $76 \%$ were concerned about diagnostic findings during the examination. The conversation group was significantly more likely to rate "good radiology" due to the opportunity for a face-to-face discussion with the radiologist, at $81 \%$ compared with $14 \%$ in the control group. This further resulted in significantly higher retention at the institution for future radiological examinations (93\% vs. $75 \%$ in the control group) and in a concurrent significantly higher assessment of the competence of the radiology department in the conversation group.

Personal contact with the attending radiologist seems to have a significant influence on the perception of the examination; thus, a heartfelt dialogue leads to a reduction of stress and discomfort and to a better handling of the examination situation [19]. The option is found to communicate concerns and fears and to gain a better understanding of the procedure, indication and possible outcomes. These are crucial aspects for people who, owing to the situation alone, are confronted with their health risks or vulnerability [18, 21]. However, professional interaction between physician and patient not only optimizes the subjectively perceived satisfaction of the patients, but also helps the treating physician to achieve more professional satisfaction [24]. In addition, improved compliance on the part of patients leads to greater examination quality $[18,33]$. These are beneficial developments that occur provided that patient autonomy is strengthened through direct communication and concomitant facilitation of participatory decision making $[19,20]$. A shift toward modern communication on equal footing and a partnership model of a doctor-patient relationship is accordingly also desirable for radiology. In any case, the research presented here suggests that prompt and personalized discussion of findings should be integra- 
ted into treatment pathways. Nevertheless, offering direct conversation in routine clinical practice is difficult to achieve due to economic reasons and physician shortages. Potenzially, this could be remedied by the development and implementation of "patient-readable" findings or by artificial intelligence support, e. $g$. , in the triage of critical findings.

In 2017 the Patient-Centered Radiology Steering Committee of the RSNA published an interesting study based on an online survey that queried 694 radiologists about the current status and awareness of patient care [24]. In addition it evaluated the extent of patient focus with extensive patient communication, and the relevant reasons for its absence in the daily routine. This shows a remarkable discrepancy between the desire and the reality in the radiologist's discussion with the patient. Although the majority of radiologists (71\%) felt that these discussions were important, only $21 \%$ of respondents reported actually having these conversations on a regular basis as part of their clinical routine. A high workload and number of examinations on large devices as obstacles were cited by $73 \%$ of the study participants. A recommended solution was to financially reward discussions with the patient to compensate for the quantitative loss of the study evaluation. This survey describes the real problem of radiology, the desire to change from a quantitative to a value-based discipline, but due to the increasing concentration of work, this is hardly achievable in reality.

A recent study from the Netherlands which analyzed online reviews of radiologists confirms that radiology is generally highly valued by patients; however, the negative reviews also show potential for improvement, especially in communication (30\% of all negative reviews) and humaneness/caring (49\% of all negative reviews) [34]. Similarly, a recent survey by the European Radiological Society of 400 patients from 22 countries shows generally high satisfaction with radiology, with $36 \%$ expressing dissatisfaction with information about the risks and benefits of examinations [35]. In this regard, $33 \%$ of patients were dissatisfied with the radiologist's availability for consultation.

\section{Radiology Department Communication with other clinical Disciplines}

In addition to the question of how and whether radiologists communicate with patients, the comprehensibility of the findings for both the patient as a medical layperson and for the referring physician is a research area of patient or person-centeredness.

Patient-comprehensible findings are one approach to making radiological results more transparent [36]. According to initial surveys, what is most desired from the patient side is language that is understandable to laypersons, in addition to an assessment and clear formulation of urgency, an explanation with glossary, and a recommendation of the steps to follow from the examination with visualization of the findings. Referring physicians primarily want clear information on the finding with recommendations on further action as well as the urgency of the finding [37].
Radiological expertise, quality of findings and communication are perceived positively overall [38]. Based on a 2008 online survey from Belgium, $87 \%$ of referring physicians surveyed consider radiology reports to be essential. An evaluation of this survey was also conducted separately for general practitioners $(n=282)$ and specialists $(n=453)$, although no separate evaluation by specialty was available within the specialist group. Nevertheless, $23.5 \%$ $(101 / 430)$ of the specialists believed that they could make a better interpretation of findings in their own discipline than the radiologist. This assessment was only $0.4 \%$ among general practitioners [12]. Referring physicians (97.4\%) agree with radiologists $(98.5 \%)$ that good clinical information and defined issues must be present. In addition to radiological findings, intercollegial discussion on a personal basis or in clinical-radiological meetings and tumor conferences is considered goal-directed and an additional benefit for patient treatment [39].

Regarding the structuring of the report text, it is interesting to note that $50.1 \%$ of the referring physicians and $50.7 \%$ of the radiologists assume that an organ region was not analyzed and reported if it is not mentioned in the report. Therefore, $84.5 \%$ of referring physicians (65.7\% radiologists) would like to see itemized reporting for complex radiology examinations. This concept is not simply to be equated with the currently frequently-requested structured reporting, but rather implies that findings are made either with topographic or hierarchical order, systematically itemized, i. e., listed individually, covering the most important organ regions [40]. But structured reporting, probably optimal in hybridization with the free text findings, supports better readability and acceptance of the results in most cases [41]. This can also be further improved by using multimedia enhancements such as linked explanations and glossaries [42] or by integrating the relevant radiological image material into the report [43].

\section{Job Satisfaction in Radiology}

In addition to the relationships of radiologists with patients and medical colleagues from other disciplines, job satisfaction is part of the subject of person-centered radiology. The question of the determining factors that move students to become radiologists and the correlation with subsequent job satisfaction during radiology training was evaluated in a recent online survey of 488 participants in the United States [44]. The intellectual challenge of the specialty was most often cited (38\%) as a key motivator, followed by enthusiasm for imaging (20\%) and the structured workflow of radiology $(20 \%)$. A large proportion of respondents who felt primarily motivated by the potential lifestyle offered by radiology experienced significantly higher levels of dissatisfaction in later residency training.

Overall, there was a high level of job satisfaction in radiology, also in comparison with other medical specialties [45]. For example, participants in a study conducted in Germany reported $65 \%$ satisfaction with their radiology residency, which was significantly lower in surveys of other disciplines, such as internal medicine (38\% [46]), urology (44\% [47]), or ophthalmology (40\% [48]). A mono-institutional free text survey demonstrated that a good 
working atmosphere with a high reputation of the radiological department as well as personal appreciation by departmental management turned out to be the most important factors for satisfaction and motivation [49]. Optimization potential was seen primarily in better communication within the team with more transparency and the influence of employees on the department's planning. In addition, continuous systematic training was perceived as an important component of satisfaction. Despite high job satisfaction, only $36 \%$ of participants with children in the survey were satisfied due to the difficult work-life balance. Due to the relatively high psychosocial stress when working in radiology, the analysis of work stress using an industry-independent questionnaire using the effort-reward (ER) model also appears interesting [50]. Simplified, the ER ratio describes the relationship between work input and reward (recognition, salary, job security, etc.), so that values $>1$ indicate an imbalance with regard to a psychosocial workload. With an ER ratio of 0.6 for the average population working full-time, the ER ratio in the survey for radiologists was 1.7 (e. g., in comparison, urology was 1.4) [47]). Among other things, a particularly positive identification with the professional image of the radiologist is suspected as a possible explanation here.

\section{Summary and Outlook}

Patient-centered or rather people-centered radiology represents a current focus in research and clinical practice in the sense of a reconsideration and reorientation of radiology to its original medical ethics and self-image. Especially in times of massively increasing digitalization and orientation towards new challenges, such as artificial intelligence as a support in the daily routine of radiology, which is characterized by work intensification, the originally medical and human component of our profession will become increasingly important.

In addition to the return to seeing radiology as an intrinsic medical activity and therefore viewing ourselves as clinically active physicians, as clinicians, numerous research approaches of person-centered radiology are emerging. Currently, most publications focus on the physician-patient relationship in our specialty. Among other things, the topics of experiencing a radiological examination during and after the imaging are evaluated. Thus, the personal discussion between radiologists and patients appears to strengthen patients' confidence and personal responsibility. Consequently, radiology is perceived positively as a distinct discipline and patient retention is better established. However, this desirable ideal of a radiologist who is always and immediately available for the discussion of findings must be viewed critically in the context of an increase in imaging, also taking economic constraints into account. Under the same dilemma of time pressure with increasing workload and the simultaneous desire of a radiologist who is always personally approachable for referring clinical colleagues, optimization of communication of findings, for example by structured or itemized reporting or should also be a goal.
Since radiologists themselves and their staff should also be taken into account in this context, the high level of psychosocial stress that still exists in a person-centered radiology department must be seen despite the high degree of job satisfaction and positive identification with the job profile, which have been confirmed in studies. Here, too, optimization must be increased in the sense of sustainable radiology.

In our approach to the topic, an evaluation of the existing literature revealed that the majority of publications simply consisted of the results of participant surveys. Scientifically, we seem to be at the beginning, so that a systematic analysis of the current situation was necessary. Currently, few studies address specific processes that might, for example, improve communication between radiologists and patients or referring clinical colleagues. Through our approach to the subject based on our narrative review, we hope this can be changed and improved in the near future, so that we as clinical interdisciplinary professionals can evolve to be not only device- and technology-centered, but human-centered as well.

\section{Conflict of Interest}

The authors declare that they have no conflict of interest.

\section{Literatur}

[1] Bardes CL. Defining "patient-centered medicine". N Engl J Med 2012; 366: 782-783. doi:10.1056/NEJMp1200070

[2] [Anonym]. In Crossing the Quality Chasm: A New Health System for the 21st Century. Washington (DC), 2001. doi:10.17226/10027

[3] Blodt S, Muller-Nordhorn J, Seifert $G$ et al. Trust, medical expertise and humaneness: A qualitative study on people with cancer' satisfaction with medical care. Health Expect 2021; 24: 317-326. doi:10.1111/hex.13171

[4] Sacristan JA. Patient-centered medicine and patient-oriented research: improving health outcomes for individual patients. BMC Med Inform Decis Mak 2013; 13: 6. doi:10.1186/1472-6947-13-6

[5] King A, Hoppe RB. "Best practice" for patient-centered communication: a narrative review. J Grad Med Educ 2013; 5: 385-393. doi:10.4300/ JGME-D-13-00072.1

[6] European Society of R. Value-based radiology: what is the ESR doing, and what should we do in the future? Insights Imaging 2021; 12: 108. doi:10.1186/s13244-021-01056-9

[7] Carlowitz HC. Sylvicultura oeconomica. Anweisung zur wilden BaumZucht. Reprint der 2. Auflage Braun, Leipzig 1732, Kessel, Remagen; 2012: 1732

[8] Kajikawa Y, Tacoa K, Yamaguchi K. Sustainability science: the changing landscape of sustainability research. Sustain Sci 2014; 9: 431-438. doi:10.1007/s11625-014-0244-x

[9] Dillard ], Dujon V, King MC. Understanding the Social Dimension of Sustainability; Routledge; 2009

[10] Flemming DJ, Gunderman RB. Should We Think of Radiologists as Nonclinicians? J Am Coll Radiol 2016; 13: 875-877. doi:10.1016/ j.jacr.2016.02.026

[11] Dalla Palma L, Stacul F, Meduri S et al. Relationships between radiologists and clinicians: results from three surveys. Clin Radiol 2000; 55: 602-605. doi:10.1053/crad.2000.0495 
[12] Bosmans JM, Weyler J], De Schepper AM et al. The radiology report as seen by radiologists and referring clinicians: results of the COVER and ROVER surveys. Radiology 2011; 259: 184-195. doi:10.1148/radiol. 10101045

[13] Turkbey B, Rosenkrantz AB. Engaging and educating patients in prostate imaging via social media. Abdom Radiol (NY) 2016; 41: 798. doi:10.1007/s00261-016-0748-1

[14] Kadom N, Nagy P, Hawkins CM. The Role of Social Media in Quality Improvement. J Am Coll Radiol 2017; 14: 577-578. doi:10.1016/j. jacr.2016.08.019

[15] Rohrl S, Dendl LM, Scharf G et al. Informed Consent in Contrast-Enhanced CT: Understanding of Risks and Identification of Possible Prognostic Factors. Rofo 2015; 187: 973-979. doi:10.1055/s-0041-104212

[16] Hoffstetter P, Hammer S, Rohrl S et al. [As time goes by - is it worth intensifying patient care during the waiting period for radiological examinations?]. Rofo 2012; 184: 1043-1048. doi:10.1055/s-0032-1313049

[17] Munn Z, Jordan Z. The patient experience of high technology medical imaging: a systematic review of the qualitative evidence. JBI Libr Syst Rev 2011; 9: 631-678. doi:10.11124/01938924-201109190-00001

[18] Lo Re G, De Luca R, Muscarneri F et al. Relationship between anxiety level and radiological investigation. Comparison among different diagnostic imaging exams in a prospective single-center study. Radiol Med 2016; 121: 763-768. doi:10.1007/s11547-016-0664-z

[19] Carlsson S, Carlsson E. 'The situation and the uncertainty about the coming result scared me but interaction with the radiographers helped me through': a qualitative study on patients' experiences of magnetic resonance imaging examinations. J Clin Nurs 2013; 22: 3225-3234. doi:10.1111/jocn.12416

[20] Smith JN, Gunderman RB. Should we inform patients of radiology results? Radiology 2010; 255: 317-321. doi:10.1148/radiol.10091608

[21] Itri JN. Patient-centered Radiology. Radiographics 2015; 35: 1835-1846. doi:10.1148/rg.2015150110

[22] Kaucher S, Khil L, Kajuter $\mathrm{H}$ et al. Breast cancer incidence and mammography screening among resettlers in Germany. BMC Public Health 2020; 20: 417. doi:10.1186/s12889-020-08534-7

[23] Latulippe K, Hamel C, Giroux D. Social Health Inequalities and eHealth: A Literature Review With Qualitative Synthesis of Theoretical and Empirical Studies. J Med Internet Res 2017; 19: e136. doi:10.2196/jmir.6731

[24] Kemp JL, Mahoney MC, Mathews VP et al. Patient-centered Radiology: Where Are We, Where Do We Want to Be, and How Do We Get There? Radiology 2017; 285: 601-608. doi:10.1148/radiol.2017162056

[25] Berlin L. Communicating results of all radiologic examinations directly to patients: has the time come? Am J Roentgenol 2007; 189: 1275-1282. doi:10.2214/Am J Roentgenol.07.2740

[26] Berlin L. Communicating results of all outpatient radiologic examinations directly to patients: the time has come. Am J Roentgenol 2009; 192: 571-573. doi:10.2214/Am J Roentgenol.08.1954

[27] Sprunt WH. Letters to the Editor: Whom Do We Serve? 1966; 87: 1125. doi:10.1148/87.6.1125c

[28] Ragavendra N, Laifer-Narin SL, Melany ML et al. Disclosure of results of sonographic examinations to patients by sonologists. Am J Roentgenol 1998; 170: 1423-1425. doi:10.2214/ajr.170.6.9609147

[29] Schreiber MH, Leonard M Jr, Rieniets CY. Disclosure of imaging findings to patients directly by radiologists: survey of patients' preferences. Am J Roentgenol 1995; 165: 467-469. doi:10.2214/ajr.165.2.7618577

[30] Lorch H, Scherer P. [Disclosure of diagnosis in ambulatory radiology practice: expectations of patients and referring physicians]. Rofo 2007; 179: 1043-1047. doi:10.1055/s-2007-963194
[31] Mangano MD, Rahman A, Choy G et al. Radiologists' role in the communication of imaging examination results to patients: perceptions and preferences of patients. Am J Roentgenol 2014; 203: 1034-1039. doi:10.2214/Am J Roentgenol.14.12470

[32] Gutzeit A, Heiland R, Sudarski S et al. Direct communication between radiologists and patients following imaging examinations. Should radiologists rethink their patient care? Eur Radiol 2019; 29: 224-231. doi:10.1007/s00330-018-5503-2

[33] Vitzthum von Eckstaedt $H$, Kitts AB, Swanson C et al. Patient-centered Radiology Reporting for Lung Cancer Screening. J Thorac Imaging 2020; 35: 85-90. doi:10.1097/RTI.0000000000000469

[34] Kwee RM, Kwee TC. Communication and empathy skills: Essential requisites for patient-centered radiology care. Eur J Radiol 2021; 140: 109754. doi:10.1016/j.ejrad.2021.109754

[35] European Society of R. Patient survey of value in relation to radiology: results from a survey of the European Society of Radiology (ESR) valuebased radiology subcommittee. Insights Imaging 2021; $12: 6$. doi:10.1186/s13244-020-00943-x

[36] Mityul MI, Gilcrease-Garcia B, Mangano MD et al. Radiology Reporting: Current Practices and an Introduction to Patient-Centered Opportunities for Improvement. Am J Roentgenol 2018; 210: 376-385. doi:10.2214/Am J Roentgenol.17.18721

[37] Perlis N, Finelli A, Lovas M et al. Creating patient-centered radiology reports to empower patients undergoing prostate magnetic resonance imaging. Can Urol Assoc J 2021; 15: 108-113. doi:10.5489/cuaj.6585

[38] Fatahi N, Krupic F, Hellstrom M. Difficulties and possibilities in communication between referring clinicians and radiologists: perspective of clinicians. J Multidiscip Healthc 2019; 12: 555-564. doi:10.2147/JMDH. S207649

[39] Dendl LM, Teufel A, Schleder S et al. Analysis of Radiological Case Presentations and their Impact on Therapy and Treatment Concepts in Internal Medicine. Rofo 2017; 189: 239-246. doi:10.1055/s-0042-118884

[40] Nobel JM, Kok EM, Robben SGF. Redefining the structure of structured reporting in radiology. Insights Imaging 2020; 11: 10. doi:10.1186/ s13244-019-0831-6

[41] Schwartz LH, Panicek DM, Berk AR et al. Improving communication of diagnostic radiology findings through structured reporting. Radiology 2011; 260: 174-181. doi:10.1148/radiol.11101913

[42] Sadigh G, Hertweck T, Kao C et al. Traditional text-only versus multimedia-enhanced radiology reporting: referring physicians' perceptions of value. J Am Coll Radiol 2015; 12: 519-524. doi:10.1016/j. jacr.2014.11.009

[43] Iyer VR, Hahn PF, Blaszkowsky LS et al. Added value of selected images embedded into radiology reports to referring clinicians. J Am Coll Radiol 2010; 7: 205-210. doi:10.1016/j.jacr.2009.10.014

[44] Matalon SA, Guenette JP, Smith SE et al. Factors Influencing Choice of Radiology and Relationship to Resident Job Satisfaction. Curr Probl Diagn Radiol 2019; 48: 333-341. doi:10.1067/j.cpradiol.2018.03.008

[45] Oechtering TH, Panagiotopoulos N, Volker M et al. Work and Training Conditions of German Residents in Radiology - Results from a Nationwide Survey Conducted by the Young Radiology Forum in the German Roentgen Society. Rofo 2020; 192: 458-470. doi:10.1055/a-1047-1075

[46] Raspe M, Vogelgesang A, Fendel ] et al. [Work and Training Conditions of Young German Physicians in Internal Medicine - Results of a Second Nationwide Survey by Young Internists from the German Society of Internal Medicine and the German Professional Association of Internists.]. Dtsch Med Wochenschr 2018; 143: e42-e50. doi:10.1055/a-0543-4544

[47] Arnold H, Meyer CP, Salem ] et al. [Work and training conditions of residents in urology in Germany: Results of a 2015 nationwide survey by the German Society of Residents in Urology]. Urologe A 2017; 56: 13111319. doi:10.1007/s00120-017-0495-0 
[48] Hos D, Steven P, Dietrich-Ntoukas T. [The situation of residents in ophthalmology in Germany: Results of an online survey]. Ophthalmologe 2015; 112: 498-503. doi:10.1007/s00347-015-0030-x

[49] Unterweger M, Imhof S, Mohr H et al. [Which factors influence job satisfaction and motivation in an institute of radiology?]. Praxis (Bern 1994) 2007; 96: 1299-1306. doi:10.1024/1661-8157.96.35.1299
[50] Siegrist ], Wege N, Puhlhofer F et al. A short generic measure of work stress in the era of globalization: effort-reward imbalance. Int Arch Occup Environ Health 2009; 82: 1005-1013. doi:10.1007/s00420-0080384-3 